\title{
Perspective of the novel coronavirus (2019-n-CoV) in Mexico
}

\author{
Adrian Camacho-Ortiz* \\ Epidemiology Service, University Hospital “Dr. José Eleuterio González", Autonomous University of Nuevo Leon, Monterrey, Nuevo León, Mexico
}

By speculating, we construct theories without solid evidence, and by estimating, we calculate approximately the impact or how large something is or will be. It seems that over the past few weeks, we have been doing a lot of both.

At the moment, we are in the midst of an outbreak spreading throughout the globe arising from China, which has now shown to be actively transmitting from person to person in other parts of the world 1 . In this phase of an outbreak, estimations and speculation tend to pour the internet with various numbers, although alarming may not be representative after all ${ }^{2}$. Although we have a new strain of coronavirus (SARS-CoV-2) causing an impressive number of infected patients, it is also true that this has caused quite a bit of panic.

The COVID-19 (Coronavirus Disease 2019) outbreak has led to estimates and speculations worldwide, and Mexico is not the exception. To date, roughly 18 suspected cases of COVID-19 have been followed in Mexico without a confirmed case since the outbreak start$\mathrm{ed}^{3}$; this has caused concerns and led many to believe that the Mexican health-care system is not prepared for a pandemic of these types of viruses, and they are right, it is not prepared; but the question is, is any health-care system in the world really prepared?

Fortunately, this is not an entirely new pandemic, although, from a microbiologic standpoint, the strain is different; it shares some similarities with other CoVs. Nevertheless, its origins are under investigation ${ }^{4,5}$. However, from the epidemiological aspect, it is somewhat familiar; starting with a cluster of pneumonia cases from China with an unidentified virus, then initially, the source is pinpointed, followed by slow and incomplete international reports. Afterward, there is a rapid spread of cases that reach various regions, then human-to-human transmission is proven, and finally, an animal source is found. We have previously seen similar scenarios during other outbreaks such as severe acute respiratory syndrome virus (SARS-CoV) ${ }^{6}$, influenza $A H 5 N 1^{7}$, influenza $A H 7 N^{8}$, and from another region, Middle Eastern respiratory syndrome (MERS-CoV) 9 . None of the aforementioned viruses made it to Mexico (at least confirmed cases). What the Mexican population did experience was the 2009 influenza pandemic ${ }^{10}$. A little more than 10 years ago that pandemic rapidly spreads throughout the country, causing thousands of cases and numerous deaths. That pandemic gave us a clear picture of what the health-care structure is capable of supporting, and although it did bend, it did not break.

To this date, the principal threat comes from national or foreign travelers visiting China and Southeast Asia. The Mexican Health Ministry must have a secure screening process in the ports of international entry, which is a complex task considering there are three direct flights from China to Mexico and the US-Mexico border that gives way to indirect tourism. Making the situation more cumbersome during 2018 alone, almost 168,000 Chinese citizens traveled to Mexico, Chinese tourists to Mexico have increased from 47,810 in 2012 to 167,663 in 2018 , a $250 \%$ increase with an annual growth average of $23.3 \%$.

Changing political and economic conditions in Mexico raise more speculation. Since 2009, three different political parties have governed the country. Andrés

\footnotetext{
Correspondence:

*Adrian Camacho-Ortiz

E-mail: acamacho_md@yahoo.com

Date of acceptance: 12-02-2020 DOI: 10.24875/RMU.M20000040

1665-5796/๑ 2020 Universidad Autónoma de Nuevo León. Published by Permanyer. This is an open access article under the CC BY-NC-ND license (http://creativecommons.org/licenses/by-nc-nd/4.0/).

Available online: $17-03-2020$

Medicina Universitaria. 2020;22(1):6-7 www.medicinauniversitaria.org
} 
Manuel López Obrador, the current president, has made many changes that could play a decisive role when facing an epidemic. Significant federal budget reductions for research were made in 2019 and will worsen in 2020. The transition from health-care coverage between the "Seguro Popular" to the "Instituto de Salud para el Bienestar" (INSABI) has many healthcare administrators worried. They fear that the extent of coverage provided by the latter will not suffice the needs of the population along with the reports of scant medication from many public hospitals.

That being said, concerning aspect of concern is that the Mexican population did not seem to learn from the 2009 influenza pandemic. Influenza vaccination coverage is extremely low and it is due to two main factors, the first being the many popular myths and misconceptions regarding influenza vaccination and the second is the erratic availability of the vaccine.

One of the features of SARS and the 2009 pandemic influenza that SARS-CoV-2 shares is the significant role in the economic and social consequences. The previous experience with SARS-CoV and MERS-CoV suggests that, like other CoVs, the transmission of SARS-CoV-2 probably occurs by means of large droplets and contact, and less so by means of aerosols, thus basic hand hygiene is the mainstay of prevention measures for public health. This also worked in successfully reducing SARS transmission and regularly works for influenza prevention.

Many questions are still unanswered and many more will appear during this outbreak; some aspects remain obscure such as optimal treatment, vaccination, and subsequent immunity, just to share a few, but as in other pandemics, early in the course of an outbreak severe cases tend to dominate reports and, subsequently, when diagnostic tests and surveillance improve, a better panorama emerges, and only then, we will understand the behavior of the disease. Thus, caution and not panic is in order. It is rare that an outbreak of this magnitude gives you an early warning and a good head start therefore the mexican population and their health-care officials should learn from other countries and from their history facing pandemics. The Mexican population and their health-care officials should learn from other countries and from their history facing pandemics. They should estimate the impact of widespread transmission on national soil and anticipate countermeasures for containment; the "bend, but do not break" phenomenon that we lived in 2009 may not repeat itself if we fail to act.

\section{References}

1. Rothe C, Schunk M, Sothmann P, Bretzel G, Froeschl G, Wallrauch C, et al. Transmission of 2019-nCoV infection from an asymptomatic contact in Germany. N Engl J Med. 2020. doi: 10.1056/NEJMc2001468.

2. Nishiura H, Jung SM, Linton NM, Kinoshita R, Yang Y, Hayashi K, et al. The extent of transmission of novel coronavirus in Wuhan, China, 2020. J Clin Med. 2020:9:330.

3. Comunicado Tecnico Diario de la Direccion General de Epidemiologia de Mexico. Available from: https://www.gob.mx/cms/uploads/attachment/ file/531556/Comunicado_Tecnico_Diario_2019nCoV_2020.02.03.pdf. [Last accessed on 2020 Feb 03].

4. Paraskevis D, Kostaki EG, Magiorkinis G, Panayiotakopoulos G, Sourvinos G, Tsiodras S. Full-genome evolutionary analysis of the novel corona virus (2019-nCoV) rejects the hypothesis of emergence as a result of a recent recombination event. Infect Genet Evol. 2020;79:104212.

5. Ji W, Wang W, Zhao X, Zai J, Li X. Homologous recombination within the spike glycoprotein of the newly identified coronavirus may boost cross-species transmission from snake to human. J Med Virol. 2020; 92(4):433-440.

6. Severe acute respiratory syndrome (SARS). Wkly Epidemiol Rec. 2003; 78:81-3.

7. Mounts AW, Kwong H, Izurieta HS, Ho Y, Au T, Lee M, et al. Case-control study of risk factors for avian influenza A (H5N1) disease, Hong Kong, 1997. J Infect Dis. 1999;180:505-8.

8. Tanner WD, Toth DJ, Gundlapalli AV. The pandemic potential of avian influenza A(H7N9) virus: a review. Epidemiol Infect. 2015;143:3359-74.

9. Zaki AM, van Boheemen S, Bestebroer TM, Osterhaus AD, Fouchier RA Isolation of a novel coronavirus from a man with pneumonia in Saudi Arabia. N Engl J Med. 2012;367:1814-20.

10. Perez-Padilla R, de la Rosa-Zamboni D, Ponce de Leon S, Hernandez M, Quiñones-Falconi F, Bautista E, et al. Pneumonia and respiratory failure from swine-origin influenza $A(\mathrm{H} 1 \mathrm{~N} 1)$ in Mexico. N Engl J Med. 2009; 361:680-9. 